\title{
ЛИТО- И МОРФОДИНАМИКА ВЕРШИНЫ НАРВСКОГО ЗАЛИВА
}

Дан обзор изменения литологических показателей пляжевых песков Нарвского залива за 5-летний $(1982-1987)$ период наблюдений. Закономерное укрупнение среднего размера песчаных частиц за этот период четко указывает на продолжение и углубление процесса размыва пляжевых наносов западнее устья р. Нарва. Выводы, сделанные по изменению литологических показателей, подтверждают геоморфологические признаки развития вершины Нарвского залива за последние 10-12 лет.

Расположенный в вершине Нарвского залива курорт Нарва-Йэсуу (Усть-Нарва) известен с конца прошлого столетия своими прекрасными пляжами, сосновым бором, дюнным ландшафтом и оздоровительным климатом. Общая протяженность песчаных берегов в вершине залива около 25 км. В настоящее время наиболее интенсивно используется под пляжи песчаная полоса юго-западнее устья р. Нарва длиной 6-7 км и шириной 50-60 м, окаймленная в левобережной зоне древними дюнами высотой до 10 м и вековыми соснами. В западном направлении песчаный пляж постепенно сужается и в 10 11 км от устья, перед клифом Утрия, не превышает 10-15 м. В этом же районе песчаный берег постепенно переходит в песчано-гравийногалечный. В 4-5 км западнее устья, перед древними дюнами, появляется полоса невысоких (до 3-4 м) авандюн, свидетельствующих o современном (или недавнем) накоплении этих береговых наносов.

Северо-восточнее устья р. Нарва песчаный берег простирается почти на 15 км до пос. Кирьямо, где он сравнительно быстро переходит в гравийно-галечный. В северном направлении, вдоль западного берега п-ова Курголово, распространены абразионные моренные берега. В границах аккумулятивного песчаного берега, т. е. на протяжении первых 14-15 км, песчаный пляж окаймлен полосой авандюн. В сторону суши прослеживается еще несколько серий невысоких, недавно образовавшихся дюнных валов. Все это указывает на то, что аккумулятивные процессы в этом районе, начавшиеся столетия тому назад (Martin, Schwartz, 1988), продолжаются по сей день.

Тем не менее начиная с 1975 г. пляжи курортной зоны НарваИыэсуу неоднократно подвергались сильным штормовым разрушениям (Orviku, 1987). Во время ураганных штормов 1975, 1982, 1983, 1986 гг. с пляжа были унесены значительные массы песка. Размыву подверглись даже подножия древних дюн. Наиболее сильные разрушения имели место на 2,5-километровом участке береговой зоны западнее устья р. Нарва.

* Eesti Teaduste Akadeemia Geoloogia Instituut (Институт геологии Академии наук Эстонии). EE0105 Tallinn, Estonia pst. 7. Estonia.

** Всесоюзный научно-исследовательскйй геологический институт им. А. П. Қарпинского. 193026 Санкт-Петербург, Средний пр. 74. 
Были случай, когда за 1-2-суточный шторм песчаный берег с дюнами отступал до 5 м, гибли прибрежные сооружения и вековые деревья. За один шторм 1975 г. с одного погонного метра пляжа было унесено около $20 \mathrm{~m}^{3}$ песка. В результате разрушительного действия ветров пляж стал низким, влажным, ухудшилось общее природное состояние берега в курортной зоне. Во время зимнего шторма 1986 г. зона разрушений захватила и отдаленные участки в западном и северовосточном направлениях, где были размыты пляж и подножия авандюн.

В целях установления причин усиливающегося размыва берега и выработки оптимальных вариантов его восстановления Институтом геологии АН Эстонии совместно с ГПИ «Эстмелиопроект» в 1981 1982 гг. проводились лито- и морфодинамические исследования в вершине Нарвского залива. Уже в 1983 г. Нарвскому горисполкому был выдан проект о реконструкции пляжа Нарва-Иыэсуу. К сожалению, многие наши рекомендации по различным причинам были оставлены без внимания, процессы же размыва продолжаются и теперь.

В 1987 г. в этом же районе проводились береговые и прибрежноморские исследования сектором методики геологической съемки шельфа ВСЕГЕИ.

Не касаясь в данной статье причин размыва и предложенных мероприятий по защите и восстановлению пляжей и природного равновесия, ниже приведем некоторые лито- и морфодинамические характеристики береговой зоны, литологии пляжевых и дюнных песков и рыхлого материала подводного берегового склона, полученные в результате анализа и сопоставления результатов геологических работ 1982 и 1987 гг.

Так как береговая зона испытывает довольно закономерные изменения энергетических условий, то естественно предположить, что структурный состав песков каждой из составляющих ее микрофаций (пляж, подводный береговой склон, дюны) будет отражать эти условия.

Для подробной характеристики осадков береговой зоны Нарвского залива было проанализировано около 200 поверхностных проб песков дюн, пляжа и подводного берегового склона, отобранных от клифа Утрия на западе до пос. Кирьямо на севере побережья в 1982 и 1987 гг.

Гранулометрический многофракционный анализ песков был проведен на стандартных наборах сит от 2,5 до 0,01 мм с модулем 10 на ротапах фирм «Fritsch» и «Retsch». Особое внимание было уделено морфометрическому анализу частиц песчаной размерности 0,3150,25 мм, который был сделан на вибросепараторе K-1780, где частицы одного размера могут быть разделены по форме на 13 классов - от окатанных до угловатых (табл. 1). Механизм разделения частиц по форме в зависимости от их коэффициента трения заключается в следующем: частицы одного размера под действием вибрации движутся по вогнутой наклонной шероховатой поверхности снизу вверх в сторону увеличения угла наклона. При определенном угле скатывающая сила, действующая на частицу, становится равной силе трения ее о поверхность, частицы перестают двигаться вверх и, благодаря поперечному наклону поверхности, попадают в приемную ячейку. Более окатанные частицы, обладающие меньшим коэффициентом трения, попадают в первые, нижние ячейки, а менее окатанные с большим коэффициентом трения, - в верхние. Скорость осаждения частиц, определяемая взаимодействием текучей среды и отдельного зерна для тел с одинаковым по площади поперечным сечением (размером) и плотностью при постоянных параметрах течения, обратно пропорциональна корню квадратному из коэффициента торможения, завися- 
О人кананость частиц с различными коэффициентами трения

Roundness of grains with different friction coefficients

\begin{tabular}{c|c|c}
\hline Класс окатанности & Коэффициент трения & $\begin{array}{c}\text { Окатанность по шкале } \\
\text { Хабакова }\end{array}$ \\
\hline 1 & 0,18 & \\
2 & 0,21 & окатанные \\
3 & 0,25 & \\
4 & 0,28 & \\
5 & 0,32 & полуокатанные \\
6 & 0,36 & \\
7 & 0,39 & угловато-окатанные \\
8 & 0,43 & сглаженные \\
9 & 0,49 & \\
10 & 0,54 & угловатые \\
11 & 0,60 & \\
12 & 0,63 & 0,65
\end{tabular}

щего от коэффициента трения частицы (ее формы) (Петтиджон и др., 1976). Поэтому описанный механизм разделения частиц по форме на вибросепараторе может служить в первом приближении моделью дифференциации частиц в процессе транспортировки их в природных условиях.

Результаты гранулометрического и морфометрического анализов были обработаны на ЭВМ ЕС 1033 по специальным программам. Для песчаных фракций $(2-0,05$ мм) были определены медианный и средний размеры, а также другие характеристики по Фолку и Варду (Folk, Ward, 1957).

Отложения берегового склона Нарвского залива представляют собой преимущественно тонко- и мелкозернистые, хорошо отсортированные $(\sigma=0,6-1,5)$ пески, практически не содержащие ни алевритовой, ни крупнозернистой составляющих, а среднезернистая представлена обычно лишь долями процента.

В южной части залива эти пески на 7-10-метровой глубине сменяются исключительно тонкозернистыми разностями со значительной примесью алеврита и скоплениями органики. На севере у пос. Курголово эти тонко- и мелкозернистые прибрежные пески сменяются грубообломочными отложениями, маркирующими подводные выходы морен.

Пески пляжа, простирающегося от клифа Утрия на западе до пос. Кирьямо на севере побережья Нарвского залива, - мелкозернистые, хорошо отсортированные, причем медианный размер практически совпадает со средним.

Сравнение данных гранулометрических анализов пляжевых отложений 1982 и 1987 гг. (рис. 1) показало, что за пять лет тенденция изменения медианного размера песчаных частиц вдоль береговой линии Нарвского залива сохранилась. Произошло лишь некоторое увеличение этого размера и улучшение сортировки материала (табл. 2), что может быть связано с усилением гидродинамической активности моря, в результате чего более мелкий материал, не соответствующий равновесному состоянию пляжа при повышенной волновой энергии, воздействующей на берег при новых условиях, выносится в более глубоководные области, а на пляже остается более крупный материал. Қак видно из рис. 1, на южном и центральном участках 
побережья залива не происходит практически никакого изменения крупности песка вдоль берега, т. е. нет дифференциации материала, обычно характерной для районов абразии берега, откуда материал исключительно выносится на подводный береговой склон.

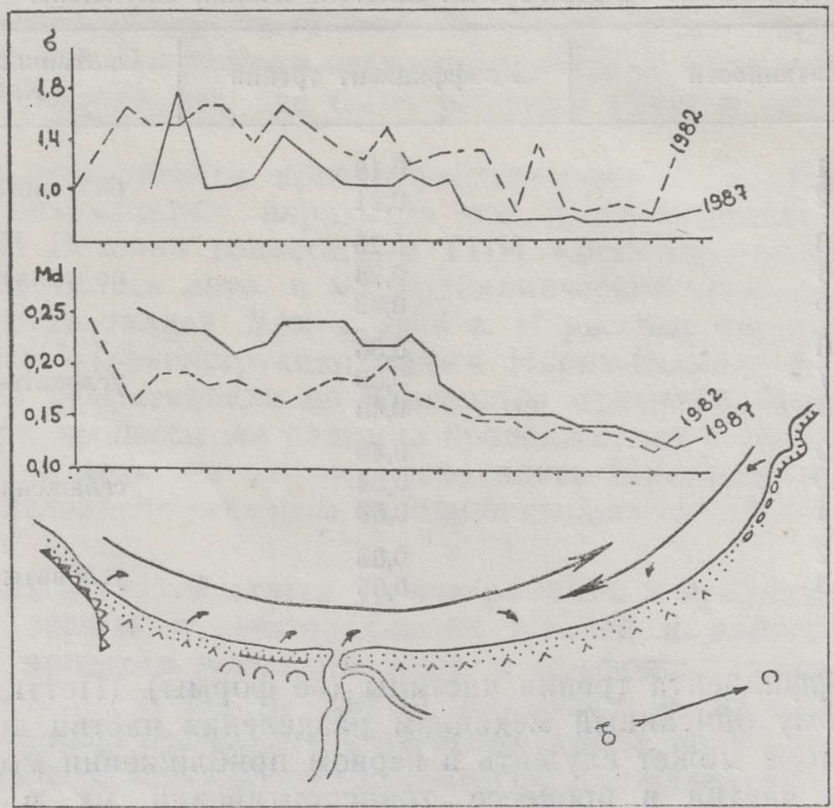

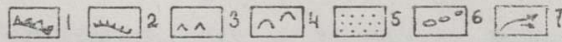

Рис. 1. Изменение значений медианного размера песчаных частиц (Md) и их сортировки $(\sigma)$ вдоль береговой линии Нарвского залива за пять лет.

1 - клиф, 2 - абразионный уступ, 3 - авандюны, 4 - дюны, 5 - песок, 6 гравий и галька, 7 - направление перемещения наносов.

Fig. 1. Changes of the median diameter $(M d)$ and sorting $(\sigma)$ of sand grains along the shoreline of Narva Bay during five years.

1 - cliff, 2 - scarp, 3 - foredune, 4 - dune, 5 - sand, 6 - gravel and shingle, 7 - direction of beach sediments movement.

Таблица 2

\section{Средний гранулометрический состав отложений береговой зоны Нарвского залива, \%}

Table 2

Average grain-size composition of beach sediments of Narva Bay, \%

\begin{tabular}{|c|c|c|c|c|c|}
\hline \multirow{2}{*}{ Микрофации } & \multicolumn{3}{|c|}{ Гранулометрические фракции, мм } & \multirow{2}{*}{$\begin{array}{c}\text { Медиан- } \\
\text { ный } \\
\text { размер } \\
\text { частиц }\end{array}$} & \multirow{2}{*}{$\begin{array}{l}\text { Коэффи- } \\
\text { циент } \\
\text { сорти- } \\
\text { ровки }\end{array}$} \\
\hline & $0,5-0,25$ & $0,25-0,1$ & $0,1-0,05$ & & \\
\hline Мелководье & 1 & 33 & 66 & 0,09 & 1,0 \\
\hline $\begin{array}{l}\text { Пляж } \\
\text { участок абразии }\end{array}$ & & & & & \\
\hline $\begin{array}{l}1982 \mathrm{r} . \\
1987 \mathrm{r} .\end{array}$ & $\begin{array}{l}24 \\
35\end{array}$ & $\begin{array}{l}74 \\
64\end{array}$ & $\begin{array}{l}2 \\
1\end{array}$ & $\begin{array}{l}0,19 \\
0,23\end{array}$ & $\begin{array}{l}1,5 \\
1,1\end{array}$ \\
\hline $\begin{array}{c}\text { участок транзита } \\
1982 \text { г. } \\
1987 \text { г. }\end{array}$ & $\begin{array}{l}6 \\
1\end{array}$ & $\begin{array}{l}90 \\
96\end{array}$ & $\begin{array}{l}4 \\
3\end{array}$ & $\begin{array}{l}0,14 \\
0,16\end{array}$ & $\begin{array}{l}1,1 \\
0,8\end{array}$ \\
\hline $\begin{array}{l}\text { Авандюны } \\
\text { участок транзита } \\
\text { участок абразии }\end{array}$ & $\begin{array}{r}4 \\
22\end{array}$ & $\begin{array}{l}95 \\
77\end{array}$ & $\begin{array}{l}1 \\
1\end{array}$ & $\begin{array}{l}0,16 \\
0,21\end{array}$ & $\begin{array}{l}0,9 \\
1,1\end{array}$ \\
\hline
\end{tabular}


Далее к северу, примерно в 3 км от устья р. Нарва, начинается довольно быстрое уменьшение медианного размера частиц с юга на север - до 1,5 раза на протяжении 10 км. В этом районе происходит явная дифференциация материала вдоль пляжа, что характерно для участков динамического равновесия. Интересно, что одновременно довольно сильно улучшается и сортировка материала (рис. 1).

Морфометрический состав наносов пляжа довольно однороден, хотя и можно отметить, что окатанность песчаных частиц с юга на север несколько ухудшается, как ухудшается и их сортировка (табл. 3). Это явление связано также с дифференциацией частиц по форме в процессе их транспортировки как поперек береговой линии, так и вдоль неe.

Таблица 3

Морфометрический состав отложений береговой зоны Нарвского залива

Table 3

Morphometrical composition of beach sediments of Narva Bay

\begin{tabular}{|c|c|c|c|c|c|c|}
\hline \multirow[b]{2}{*}{ Микрофации } & \multicolumn{5}{|c|}{ Окатанность, $\%$} & \multirow{2}{*}{$\begin{array}{c}\text { Коэффи- } \\
\text { циент } \\
\text { сорти- } \\
\text { ровки }\end{array}$} \\
\hline & $\begin{array}{c}\text { окатан- } \\
\text { ные }\end{array}$ & $\begin{array}{c}\text { полу- } \\
\text { окатан- } \\
\text { ные }\end{array}$ & $\begin{array}{l}\text { углова- } \\
\text { то-ока- } \\
\text { танные }\end{array}$ & $\begin{array}{c}\text { сгла- } \\
\text { женные }\end{array}$ & $\begin{array}{c}\text { углова- } \\
\text { тые }\end{array}$ & \\
\hline
\end{tabular}

Пляж

участок абразии

участок динамического

равновесия

Авандюны

23

20

9

Дюны

$\begin{array}{ll}3 & 56 \\ 20 & 51 \\ 9 & 41 \\ 4 & 21\end{array}$

20
23
37
37

20

23

37

37

$\begin{array}{rrr}2 & 0 & 2,0 \\ 4 & 0 & 2,2 \\ 11 & 2 & 2,2 \\ 26 & 12 & 2,8\end{array}$

На участках абразии при преимущественном движении песчаного материала от пляжа в сторону подводного склона происходит вынос угловатых частиц с пляжа и накопление на нем более окатанных, так как угловатые частицы обладают большим коэффициентом трения и легче переносятстя в потоке, в то время как окатанные, с меньшим коэффициентом трения, выпадают раньше и остаются на пляже.

На участках же, где происходит поочередное перемещение материала на пляж и от пляжа, появляется несколько большее количество хуже окатанных частиц.

Генетически связанные с пляжевыми отложениями пески дюн и по своему гранулометрическому составу весьма близки к ним. По морфометрическому же составу (табл. 3) они отличаются от песков пляжа: увеличивается количество угловато-окатанных частиц, уменьшается количество окатанных, увеличивается среднее значение класса окатанности, причем если на авандюнах оно изменяется в пределах 4,96,0 , то на следующих грядах достигает 6,8. Это свидетельствует о дифференциации песка при переносе уже в ветропесчаном потоке. Процесс этот аналогичен процессу, происходящему в водной среде. В воздушном потоке, как и в водном, при транспортировке частиц происходит их дифференциация по форме. Эоловая обработка обломочного материала в береговых дюнах имеет место лишь в очень малой степени (Минкявичюс, 1968; Ромм, Кривулина, 1985). Определяющим изменение окатанности в процессе формирования дюн фактором является дифференциация материала по форме в ветропесчаном потоке: угловатые частицы, имеющие больший коэффициент трения. со средой, переносятся воздушным потоком легче, нежели окатанные, 
выпадающие из потока довольно быстро. Из-за переменчивости ветра ухудшается и сортировка материала. Для выявления естественных групп микрофаций песчаных отложений прибрежной зоны Нарвского залива и выяснения их взаимосвязи полученные данные были проанализированы методом главных компонент. Аппарат факторного анализа позволяет выявить наличие структуры в большом числовом массиве данных путем получения минимального числа переменных, содержащих то же количество информации. Были проанализированы две выборки, в одной из которых в качестве признака было взято процентное содержание каждой из гранулометрических фракций в 103 образцах, а в другой - процентное содержание в каждом из морфометрических классов в 46 образцах.

Анализ матрицы факторных нагрузок первой выборки показал, что три главных фактора, дающих до $67 \%$ в суммарную дисперсию, могут

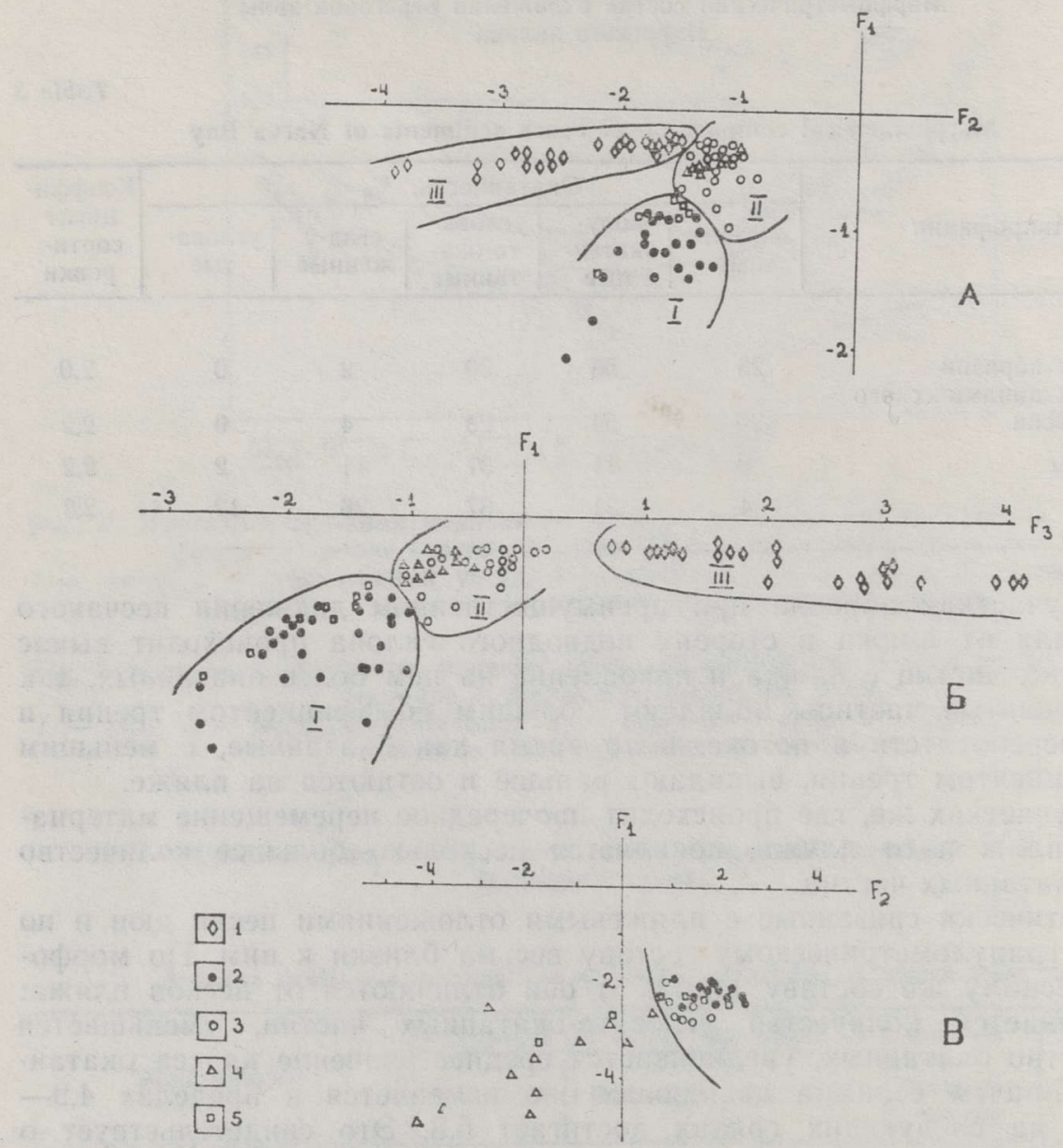

Рис. 2. Диаграммы распределения данных по гранулометрическому (А и Б) и морфометрическому (B) составу песчаных отложений вершины Нарвского залива в 1 плоскости двух факторов.

1 - мелководье, 2 - участок абразии пляжа, 3 - участок динамического равновесия пляжа, 4 - участок абразии дюн, 5 - участок динамического равновесия дюн.

Fig. 2. Diagrams of the distribution of grain-size (A, B) and morphometric (B) composition data obtained on beach sediments from the top of Narva Bay.

1 - shallow water, 2 - area of beach abrasion, 3 - area of dynamic equilibrium of beach, 4 - area of dunes' erosion, 5 - areas of dunes' dynamic equilibrium. 
быть оценены как значимые. Эти факторы указывают на причинные процессы, воздействующие на изменение гранулометрического состава наносов. Он может изменяться в результате либо абразии частиц, либо дифференциации материала в процессе его транспортировки. Но поскольку абразия частиц - процесс чрезвычайно длительный и не может иметь существенного значения при транспортировке песчаного материала в пределах нескольких километров, то эту причину, видимо, придется исключить, так как дифференциация материала целиком зависит от динамики среды осадконакопления.

Первый фактор имеет высокую отрицательную корреляцию с нагрузками на грубо- и крупнозернистые фракции $(1,25-1,0$ и $1,0-0,8$ мм), т. е. при увеличении энергии волн в прибрежной зоне первый фактор должен уменьшаться, так как чем более высокоэнергетичен пляж, тем более крупный материал на нем остается. Второй фактор связан довольно высокой отрицательной корреляцией с тонкозернистыми $(0,1-$ 0,08 мм) песками и положительной с грубозернистыми $(1,6-1,25$ мм). Третий фактор положительно коррелируется с нагрузками на тонкозернистые $(0,1-0,08$ мм) разности, т. е. прямо коррелируется с уменьшением интенсивности динамики среды осадконакопления.

Диаграммы распределения данных в плоскости главных факторов - первого и второго (рис. 2, А), первого и третьего (рис. 2, Б) позволяют довольно четко разграничить отложения, сформировавшиеся в различных динамических условиях.

Наибольшая энергетическая активность проявляется, безусловно, на пляжах, подвергающихся размыву (поле I на рис. 2, А и Б). Пески этого участка побережья (рис. 3), а также сформировавшиеся за их счет отложения дюн имеют наивысшие отрицательные значения первого и третьего факторов, обладают наибольшими средним и медианным размерами и наихудшей сортировкой.

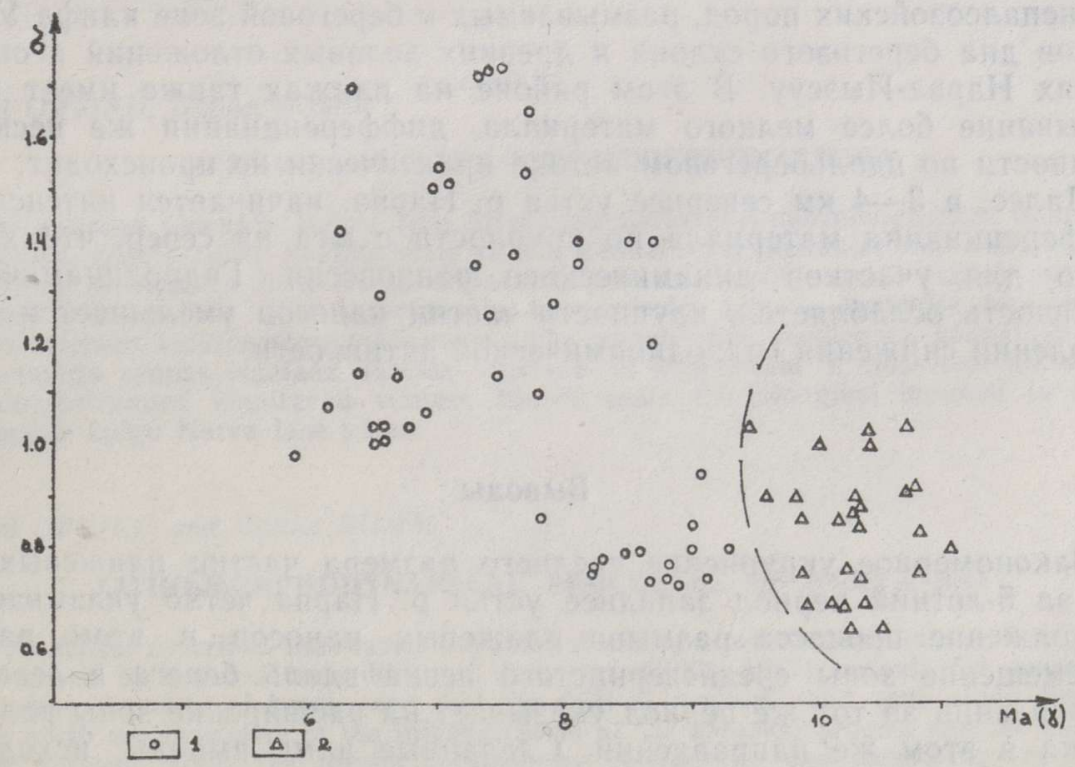

Рис. 3. Диаграмма распределения отложений пляжа и мелководья по среднему диаметру частиц $(\mathrm{Ma}(\gamma))$ и их сортировке $(\sigma)$.

1 - пляж, 2 - мелководье.

Fig. 3. Diagram of the distribution of beach and shallow water sediments based on mean diameter $(\mathrm{Ma}(\gamma))$ and sorting $(\sigma)$.

1 - beach, 2 - shallow water. 
Пески участка динамического равновесия (поле II на рис. 2, А и Б) отлагались в гидродинамически более спокойных условиях, их средний и медианный размеры явно меньше, а сортировка значительно лучше (рис. 3 ).

В самых спокойных условиях происходит, очевидно, отложение песков берегового склона (второй фактор отрицательный, третий положительный, первый стремится к нулю). Поле распространения этих песков (поле III на рис. 2, А и Б) вытянуто вдоль оси абсцисс. Факторная диаграмма данных морфометрического анализа (рис. 2, В) дает возможность довольно легко разграничить отложения пляжа и сформировавшихся за их счет дюн. Следует, правда, заметить, что большинство дюнных песков участка абразии попало в поле пляжевых песков, что, видимо, закономерно, так как на абразионных участках материал подвергается эоловой обработке значительно меньше.

При рассмотрении литодинамики современных осадков Нарвского залива следует учитывать тот факт, что гидродинамика этого бассейна довольно активна, так как залив представляет собой пологую вогнутую дугу, открытую северо-западным господствующим ветрам, а высота ветровых волн достигает 3,5 м. Отметим также очень небольшие уклоны подводного берегового склона. Все это создает благоприятные условия для возникновения вдольбереговых и компенсационных прибрежных течений. Так как миграция и дифференциация материала в береговой зоне регулируются почти исключительно движением водных масс за счет течений и волнений при взаимодействии волн $\mathrm{c}$ берегом, то по результатам вышеизложенных исследований можно изучить литодинамические процессы, приведшие к образованию прибрежных отложений.

По всей вероятности, вдоль берега Нарвского залива с запада на восток и далее на север движется прибрежный поток наносов. Зарождается он в западной части залива, где происходит абразия нижнепалеозойских пород, размываемых в береговой зоне клифа Утрия, песков дна берегового склона и древних эоловых отложений в окрестностях Нарва-Иыэсуу. В этом районе на пляжах также имеет место вымывание более мелкого материала, дифференциации же песка по крупности во вдольбереговом потоке практически не происходит.

Далее, в 3-4 км севернее устья р. Нарва, начинается интенсивная дифференциация материала по крупности с юга на север, что характерно для участков динамического равновесия. Гидродинамическая активность ослабляется, крупность частиц наносов уменьшается в направлении снижения гидродинамической активности.

\section{Выводы}

Закономерное укрупнение среднего размера частиц пляжевых песков за 5-летний период западнее устья р. Нарва четко указывает на продолжение процесса размыва пляжевых наносов в этом районе. Перемещение зоны среднезернистого песка вдоль берега в северном направлении за тот же период указывает на расширение зоны размыва пляжа в этом же направлении. Сделанные нами выводы, исходящие из изменений литологических показателей пляжевых песков, совпадают с геоморфологическими признаками развития берегов вершины Нарвского залива за последние 10-12 лет.

Изучение изменений среднего диаметра частиц пляжевых песков с одновременным определением степени окатанности позволяет с большой вероятностью выявлять зоны размыва, транзита и аккумуляции береговой зоны. 
Повторное изучение изменений названных показателей, по-видимому, позволит обнаружить процесс размыва пляжей в его начальной стадии.

Авторы убеждены, что если бы аналогичный цикл работ был проведен десятилетием раньше появления первых явных морфологических признаков размыва в 1975 г., удалось бы своевременно предсказать многие опасные тенденции в развитии Нарвского пляжа.

Повторное изучение литологии береговых наносов позволит достоверно выявить тенденции развития того или иного конкретного участка современной береговой зоны.

\section{ЛИТЕРА Т У РА}

Минкявичюс В. А. 1968. Изменение гранулометрического состава и степени окатанности песка в ветропесчаном потоке в зависимости от скорости ветра на подвижных дюнах косы Куршю-Нерия. - Тр. АН ЛитССР, сер. Б, 1(52), $109-118$.

Петтиджон Ф., Поттер П., Сивер Р. 1976. Пески и песчаники. Москва, Мир.

Ромм Г. М., Кривулина Ю. А. 1985. Морфометрическая характеристика песчаных отложений береговой зоны косы Куршю-Нерия. - Литология и полезные ископаемые, 1, 106-112.

Folk, R., Ward, W. 1957. Brazos River bar: a study in the significance of grain size

Martin, E., Schwartz, M. Sedimentary Petrology, 27, 1, 3-26. USSR. - B кн.: Commission on Coastal Environments. Hawks Nest, NSW Australia, 14-19 August 1988. Itinerary, Abstracts and Participants.

Orviku, K. 1987. Eesti rannik ja selle muutused. - Eesti Loodus, 11, 712-719.

Представил А. Раукас

Поступила в редакцию

6/XI 1991

Kaarel ORVIKU, Galina ROMM

\section{NARVA LAHE PARA LITO-MORFODUNAAMIKA}

On esitatud ülevaade Narva lahe liivaranna litoloogilis-morfoloogilistest muutustest viieaastase $(1982-1987)$ vaatlustsükli vältel. Rannaliivade keskmise diameetri suurenemine ning keskteralise liiva tsooni nihkumine piki randa pōhja poole viitab murrutusprotsessi süvenemisele ning murrutusala laienemisele. Liivade keskmise terajämeduse ning liivaterade kulutusastme määramine ning omavaheline võrdlemine võimaldab suure tōenäosusega rannas eraldada kulutus-, transiit- ja kuhjealasid. Rannasetete litoloogilise uurimise tulemused kinnitavad viimase $10-12$ aasta morfoloogilisi muutusi ja rannaprotsesside kulgu Narva lahe päras.

\section{Kaarel ORVIKU and Galina ROMM}

\section{LITHO-MORPHODYNAMICAL PROCESSES OF NARVA BAY}

The article describes litho-morphodynamical changes which have taken place on the sandy beach of Narva-Jōesuu during a five-year (1982-1987) period. The increase of the median diameter of beach sand and the shift of medium sand zone along the shore to the north are indicative of the intensification of the abrasion process and the extension of the abrasion area. The results obtained by determining and comparing the median diameter and roundness of sand grains enabled to distinguish areas with high probability of abrasion and transit and accumulation areas. The research into the lithologu of coastal sediments confirmed the tendencies that have taken place on Narva-Joesuu sandy beach during the last $10-12$ years. 